\title{
EDITORIAL
}

\section{ERS publications: the flagship and the fleet}

\author{
Anh Tuan Dinh-Xuan*, Vito Brusasco\#, Jadwiga A. Wedzicha", Elin Reeves ${ }^{+}$, Marc Humbert ${ }^{\S}$, \\ Tobias Welte ${ }^{f}$ and Leif Bjermer**
}

$\mathbf{R}$ eaders of scientific and medical journals will be familiar with the annual editorial from the chief editor(s) or editorial team, highlighting the aims for the year, interesting upcoming review series, statistics on submissions and impact factors, positioning alongside the competition (and what makes that journal better!), and new features and developments [1-4]. So, in keeping with tradition, the European Respiratory Journal (ERJ) brings you its yearly offering with everything that you would expect... but with a couple of twists. The first twist is that we are bringing this to you later than usual, more than midway through the year to coincide with the European Respiratory Society (ERS)'s congress in Vienna, Austria, from September 1 to 5, 2012. This gives us an opportunity to reflect on what has happened this year and check that the editorial aims that were set at the start of the year are being met. The second twist is that we will be introducing to you (or reminding you about, for those already familiar with the Society) the other publications in the ERS portfolio. The publications are central to the aims of the ERS, being one of the society's "pillars", in that they are a forum for sharing and disseminating knowledge, and ultimately alleviating suffering from respiratory disease and promoting lung health. If the ERJ is considered as the official scientific journal of the ERS - one might say a flagship - then what of the rest of the fleet?

\section{YOUR FLAGSHIP: SAILING THE HIGH SEAS}

Looking first at the ERJ, we are pleased to be able to announce the 2011 impact factor is 5.895, which means that the journal has regained the bronze medal position of third in the respiratory systems journals list.

The ERJ attracts increasingly high-quality science and this reputation manifests itself in the number of manuscript submissions, which exceeded 2,280 in 2011 (fig. 1). Although a European journal in name, the ERJ is truly global in outlook and reach, with about $40 \%$ of submissions coming from outside Europe (fig. 2). The workflow keeps us incredibly busy and yet we have managed (we hope!), together with our editorial board, to ensure that the author experience is as efficient and painless as possible, by committing to a median verdict time of 18 days

\footnotetext{
*Dept of Cardiorespiratory Medicine, Cochin Hospital, Paris and ${ }^{\S}$ Univ. Paris-Sud, Hôpital Bicêtre, AP-HP Le Kremlin-Bicêtre, Paris, France. " Dept of Internal Medicine, University of Genoa, Genoa, Italy. "Centre for Respiratory Medicine, University College London, London and +ERS Publications Office, Sheffield, UK. ${ }^{f}$ Dept of Pulmonary Medicine, Medizinische Hochschule Hanover, Hanover, Germany. ${ }^{* *}$ Dept of Respiratory Medicine and Allergology, Heart and Lung Division, University Hospital, Lund, Sweden.

CORRESPONDENCE: J.A. Wedzicha, Centre for Respiratory Medicine, University College London, Royal Free Campus, Rowland Hill Street, Hampstead, London NW3 2PF, UK. E-mail: j.a.wedzicha@ucl.ac.uk
}

for all manuscripts. We know that immediacy is important: once accepted, articles are published online ahead of press (in ERJ In Press) usually within 2 weeks, ensuring your research can be seen as soon as possible. It goes without saying that we encourage you to continue to submit your very best papers!

In terms of noteworthy content, 2012 saw the launch of an important series on the rational use of anti-tuberculosis (TB) drugs [5-7]. These articles looked at the emergence of drugresistant TB and its correlation to inappropriate use of TB drugs. The series was further strengthened by a joint ERS/European Centre for Disease Prevention and Control task force report on the European Union standards for TB care [8], aimed at setting guidelines for the diagnosis, treatment and prevention of TB for use by clinicians and public health workers alike. These articles were highly read, well received and considered to be especially timely, given the objective of the current ERS President (Klaus F. Rabe) to bridge the health divide in Europe, focusing on tackling avoidable health inequalities and reducing the burden of associated respiratory and other diseases [9].

In April, we introduced ERJ Open, a service that enables authors to ensure that their work is made available for anyone to access online immediately upon publication. We believe this option is an important part of the ERS's response to the changing expectations of customers and funding bodies who support research and scholarly communication.

As pressure to publish for scientists and researchers shows no sign of decreasing, this has unfortunately seen a rise in publication misconduct in the scientific field. Whilst the editorial team have always been alert to this possibility occurring in the $E R J$, a helping hand has been implemented in the form of plagiarism detection software. All authors should be aware that plagiarism and self-plagiarism are taken very seriously at the $E R J$, and indeed any form of publication misconduct. In fact, all of the ERS publications are members of the Committee on Publications Ethics (COPE), and their flowcharts are used as the basis for any investigation of potential misconduct (http:// publicationethics.org/resources/flowcharts).

\section{ERR FITS THE BILL}

Steered by Marc Humbert and his editorial crew, the European Respiratory Review (ERR) provides quarterly updates on medicine, science and surgery for respiratory professionals [10]. It contains state-of-the-art reviews, editorials and correspondence, in addition to summaries of the most important recent research findings and published studies in topics such as COPD, asthma, pulmonary hypertension, interstitial lung diseases, lung cancer and TB. 


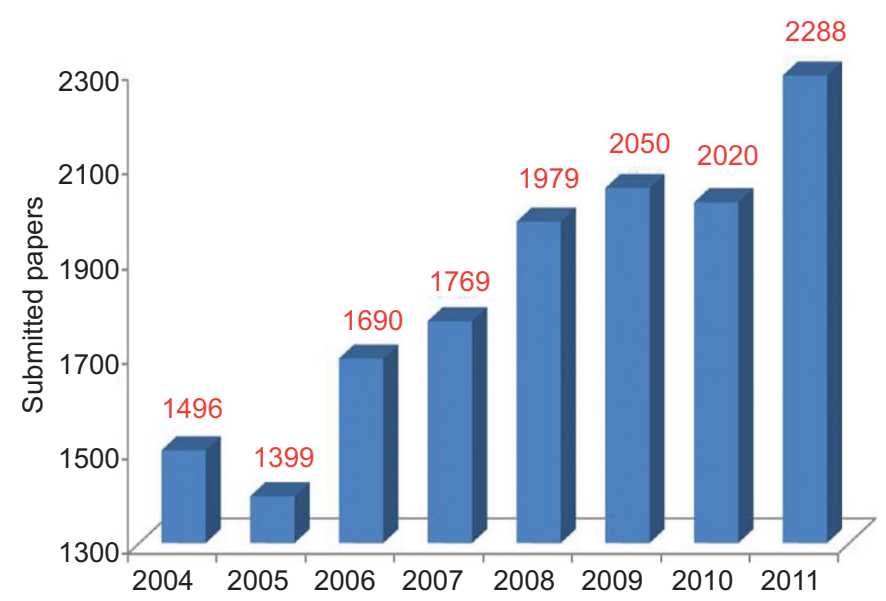

FIGURE 1. European Respiratory Journal submission trends from 2004 to 2011.

Complementing the ERS's mission of sharing knowledge, the $E R R$ is free to access (http://err.ersjournals.com), enabling anyone to read it online immediately upon publication without subscription. The ERR is also now indexed on Medline, which has greatly improved its visibility and profile.

The ERR also provides a space to cover key subjects in some depth. The June 2012 issue contained a series of articles written by members of an ERS task force on the management of workrelated asthma [11-15], which provided vital background and context to the main summary document, published in the ERJ [16]. The success of this joint venture will hopefully act as a model for future task forces.

\section{ERM: FROM STEM TO STERN}

Launched in 1995, the European Respiratory Monograph (ERM) is the ERS's quarterly book series. Each Monograph covers a specific area of respiratory medicine, providing in-depth reviews that give clinicians at all levels a concise, comprehensive guide to symptoms, diagnosis and treatment. As part of the ERS membership benefits, all members have online access to this book resource (http:/ / erm.ersjournals.com).

The editorial strategy of the ERM has been refined under the editorship of Tobias Welte over the past couple of years: topics addressed are broad enough to have wide appeal across certain areas of respiratory medicine, provide regular updates of previously addressed areas, and allow flexibility to respond to readers' needs or new emerging areas. Recent Monographs have explored orphan lung diseases, new developments in mechanical ventilation, and pulmonary hypertension.

In recognition of its value to respiratory clinicians worldwide, the ERM is now indexed in the Thomson Reuters Book Citation Index, part of the Web of Science, which allows users to now search across a range of information sources (journals, books and conference proceedings) to discover the best resources for their work via citation links.

\section{BUOYED UP BY BREATHE}

Breathe is the ERS's educational magazine-style journal, publishing review articles, editorials, case studies and self-tutorial material. It is aimed towards students, general practitioners,

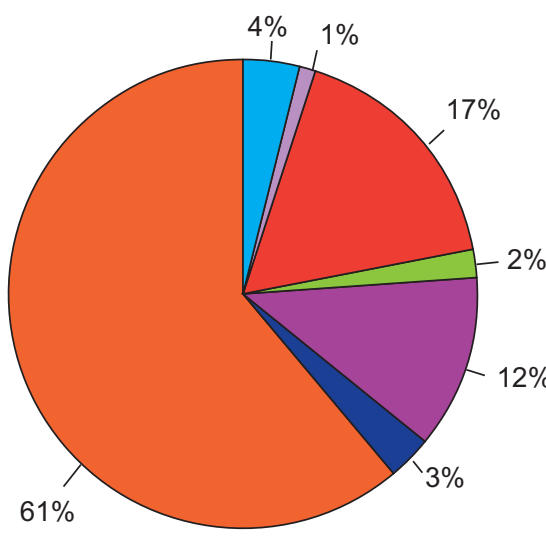
Total: 2020 manuscripts
from 62 countries

Europe 1205

Asia 335

North America 250

South America 58

Africa 13

Middle East 36

Australia and New Zealand 87

FIGURE 2. Geographical breakdown of European Respiratory Journa/ manuscript submission in 2010

nurses, technicians and anyone who requires training in respiratory medicine. Readers can even earn continuing medical education (CME) credits from reading and answering questions on selected articles. Print subscriptions are free for ERS members, non-members and libraries, and the website is free to access (www.breathejournal.org), so there is no excuse not to read it!

Under the editorship of Leif Bjermer, there has been a focus on providing a wide range of subject areas in each issue, so that readers will always be able to find something of interest when they flick through. The June 2012 issue featured several articles on sport and exercise in conjunction with respiratory health, which was excellent timing considering the global attention on the summer Olympic Games and the Forum of International Respiratory Societies initiative World Spirometry Day that took place on June 27, with the theme of "joining the race for healthy lungs". The eagle-eyed among you will have noted that Breathe also had an internal design revamp in early 2012 to refresh, renew and make content easier to read. Online statistics have shown that practical articles, such as "how to" guides, are the most popular with Breathe readers and are the most downloaded and accessed.

A reader survey was conducted in June and July and the results proved most interesting, and will serve to shape the strategy and future content of Breathe. The feedback received was incredibly positive with $96 \%$ of readers saying they would recommend the publication to a relevant colleague. The vast majority of readers rated the various article types published as excellent or good in terms of clinical and educational usefulness. One of the major areas for development in the short and long term we (and you, as our valued readers) have identified will be the Breathe website and we look forward to being able to introduce you to the improved site over the coming months.

\section{TAKING A NEW TACK}

As the prevalence of smartphones and tablets spreads, the workplace becomes less anchored to one physical location and the work/life balance becomes disrupted, accessibility and enhancing the reader experience on a small screen have become the norm. In late 2011, mobile-optimised websites were introduced for both the ERJ and ERR and now we are pleased to launch, in time for the ERS annual congress, the ERS 
publications app, providing easy access to the full text and images of both the ERJ and ERR, optimised for your iPhone and iPad, all at the touch of an icon! We plan to add ERM content to the app soon.

For those of you who are avid users of social media, the ERS publications Twitter feed (@ERSpublications) is an ideal way to keep up to date with all the latest news from the publications. The Twitter feed provides reminders on when new issues of the $E R J, E R R, E R M$ and Breathe have been published, when ERJ podcasts are available to download, and information from the editors on noteworthy papers and free content.

\section{ALL ABOARD!}

In summary, we, as the Chief Editors of the ERS publications, feel extremely pleased with the progress that our individual publications are making and we hope that you find them useful in your daily work and practice. As a portfolio, the publications offer something for respiratory professionals at all stages in their career and we encourage you to use them and recommend them to your colleagues. Enjoy!

\section{STATEMENT OF INTEREST}

E. Reeves is an employee of the ERS.

\section{REFERENCES}

1 Dinh-Xuan AT, Brusasco V. The ERJ in its 21st year of age: a smooth transition for an everlasting evolution. Eur Respir J 2009; 33: 1-2.

2 Dinh-Xuan AT, Brusasco V. Refining the changes. Or, how to modify the shape, not the spirit. Eur Respir J 2009; 34: 1.

3 Migliori GB, Soriano JB, Brusasco V, et al. ERJ peer reviewers: does this pillar of the Journal's quality need help? Eur Respir J 2011; 38 251-252.
4 Soriano JB, Brusasco V, Dinh-Xuan AT. The European Respiratory Journal makes COPD a priority. Eur Respir J 2011; 38: 999-1001.

5 Langendam MW, van der Werf MJ, Huitric E, et al. Prevalence of inappropriate tuberculosis treatment regimens: a systematic review. Eur Respir J 2012; 39: 1012-1020.

6 van der Werf MJ, Langendam MW, Huitric E, et al. Knowledge of tuberculosis-treatment prescription of health workers: a systematic review. Eur Respir J 2012; 39: 1248-1255.

7 van der Werf MJ, Langendam MW, Huitric E, et al. Multidrug resistance after inappropriate tuberculosis treatment: a metaanalysis. Eur Respir J 2012; 39: 1511-1519.

8 Migliori GB, Zellweger JP, Abubakar I, et al. European Union Standards for Tuberculosis Care. Eur Respir J 2012; 39: 807-819.

9 Humbert M. Update on the European Respiratory Review. Eur Respir J 2010; 36: 993-994.

10 Rabe KF. From the ERS President: "2012: Tackling health inequalities in Europe". http://www.ersnet.org/news/item/ 4497-ers-presidential-letter-to-members.html Date last updated: February 23, 2012. Date last accessed: June 14, 2012.

11 Maestrelli $\mathrm{P}$, Schlünssen $\mathrm{V}$, Mason $\mathrm{P}$, et al. Contribution of host factors and workplace exposure to the outcome of occupational asthma. Eur Respir Rev 2012; 21: 88-96.

12 Vandenplas O, Dressel H, Nowak D, et al. What is the optimal management option for occupational asthma? Eur Respir Rev 2012; 21: 97-104.

13 Wilken D, Baur X, Barbinova L, et al. What are the benefits of medical screening and surveillance? Eur Respir Rev 2012; 21: 105-111.

14 Heederik D, Henneberger PK, Redlich CA, et al. Primary prevention: exposure reduction, skin exposure and respiratory protection. Eur Respir Rev 2012; 21: 112-124.

15 Baur X, Aasen TB, Burge PS, et al. The management of workrelated asthma guidelines: a broader perspective. Eur Respir Rev 2012; 21: 125-139.

16 Baur X, Sigsgaard T, Aasen TB, et al. Guidelines for the management of work-related asthma. Eur Respir J 2012; 39: 529-545. 